\title{
Cyclooxygenases and lipoxygenases are used by the fungus Podospora anserina to repel nematodes
}

\author{
Roselyne Ferrari ${ }^{\mathrm{a}}$, Isabelle Lacaze ${ }^{\mathrm{b}}$, Pauline Le Faouder ${ }^{\mathrm{c}}$, Justine Bertrand-Michel ${ }^{\mathrm{c}}$, \\ Camille Oger $^{\mathrm{d}}$, Jean-Marie Galano ${ }^{\mathrm{d}}$, Thierry Durand ${ }^{\mathrm{d}}$, Stéphane Moularat ${ }^{\mathrm{b}}$, \\ Laetitia Chan Ho Tong ${ }^{a}$, Charlie Boucher ${ }^{\mathrm{a}}$, Jaafar Kilani ${ }^{\mathrm{a}}$, Yohann Petit ${ }^{\mathrm{a}}$, Océane Vanparis ${ }^{\mathrm{a}}$, \\ César Trannoy $^{\mathrm{a}}$, Sylvain Brun ${ }^{\mathrm{a}}$, Hervé Lalucque ${ }^{\mathrm{a}}$, Fabienne Malagnac ${ }^{\mathrm{a}, \mathrm{e}}$, Philippe Silar ${ }^{\mathrm{a}, *}$ \\ a Sorbonne Paris Cité, Laboratoire Interdisciplinaire des Energies de Demain (LIED), Univ. Paris Diderot, Paris F-75205, France \\ ${ }^{\mathrm{b}}$ Direction Santé Confort, Division Agents Biologiques et Aérocontaminants, Centre Scientifique et Technique du Bâtiment (CSTB), 84, avenue Jean Jaurès, Marne-la- \\ Vallée Cedex F-77447, France \\ ${ }^{\mathrm{c}}$ MetaToul-Lipidomic Core Facility, MetaboHUB, Inserm U1048, Toulouse 31 432, France \\ d Institut des Biomolécules Max Mousseron, (IBMM), CNRS, ENSCM, Université de Montpellier, UMR 5247, 15 Av. Ch. Flahault, Montpellier Cedex F-34093, France \\ e Institute for Integrative Biology of the Cell, CEA, CNRS, Université Paris-Sud, Orsay 91400, France
}

\section{A R T I C L E I N F O}

\section{Keywords:}

Lipoxygenase

Cyclooxygenase

Oxylipins

Volatile organic compounds

Podospora anserina

Fungi

\begin{abstract}
A B S T R A C T
Oxylipins are secondary messengers used universally in the living world for communication and defense. The paradigm is that they are produced enzymatically for the eicosanoids and non-enzymatically for the isoprostanoids. They are supposed to be degraded into volatile organic compounds (VOCs) and to participate in aroma production. Some such chemicals composed of eight carbons are also envisoned as alternatives to fossil fuels. In fungi, oxylipins have been mostly studied in Aspergilli and shown to be involved in signalling asexual versus sexual development, mycotoxin production and interaction with the host for pathogenic species. Through targeted gene deletions of genes encoding oxylipin-producing enzymes and chemical analysis of oxylipins and volatile organic compounds, we show that in the distantly-related ascomycete Podospora anserina, isoprostanoids are likely produced enzymatically. We show the disappearance in the mutants lacking lipoxygenases and cyclooxygenases of the production of 10-hydroxy-octadecadienoic acid and that of 1-octen-3-ol, a common volatile compound. Importantly, this was correlated with the inability of the mutants to repel nematodes as efficiently as the wild type. Overall, our data show that in this fungus, oxylipins are not involved in signalling development but may rather be used directly or as precursors in the production of odors against potential agressors. Significance: We analyzse the role in inter-kingdom communication of lipoxygenase (lox) and cyclooxygenase (cox) genes in the model fungus Podospora anserina.

Through chemical analysis we define the oxylipins and volatile organic compounds (VOCs)produce by wild type and mutants for cox and lox genes,

We show that the COX and LOX genes are required for the production of some eight carbon VOCs.

We show that COX and LOX genes are involved in the production of chemicals repelling nematodes.

This role is very different from the ones previously evidenced in other fungi.
\end{abstract}

\section{Introduction}

The complete arsenal of molecules used by microorganisms to sense and adapt to their biotic and abiotic environment is far from being known. Oxylipins derived from the oxidation of polyunstaurated fatty acids (PUFAs) are used throughout the plant, animal and fungal kingdoms to signal defense mechanisms, but also development and reproduction [1]. In fungi, their roles are well studied in the genus Aspergillus mostly through the deletion of cyclooxygenase genes (Table 1) and in this genus oxylipins are at the crossroads of several biologically-significant mechanisms, such as reproduction and growth, pathogen interactions and secondary metabolite production [2, 3]. Few genes involved in oxylipin production have been analyzed in other fungi and developmental roles may or may not be found in the studied

\footnotetext{
* Corresponding author at: Sorbonne Paris Cité, Laboratoire Interdisciplinaire des Energies de Demain, Univ Paris Diderot, case courrier 7040 Lamarck, Paris 75205, France.

E-mail address: philippe.silar@univ-paris-diderot.fr (P. Silar).
} 
Table 1

Lipoxygenase and cyclooxygenase genes in selected fungal genomes.

\begin{tabular}{|c|c|c|c|c|c|c|}
\hline & Lox Val-group & Lox Ile-group & $\operatorname{Cox}$ & Abm & Phenotypes & References \\
\hline Podospora anserina & & $\begin{array}{l}\text { PaLox1 } \\
(\text { Pa_2_4370) } \\
\text { PaLox2 } \\
(\text { Pa_6_8140) }\end{array}$ & $\begin{array}{l}\text { PaCox1 (Pa_1_4690) } \\
\text { PaCox2 (Pa_5_1240) }\end{array}$ & & See text. & This paper \\
\hline Magnaporthe grisea & MGG_08499 & & $\begin{array}{l}\text { MGG_13239 } \\
\text { MGG_10859 }\end{array}$ & MGG_04777 & $\begin{array}{l}\text { MGG_13239: No phenotype for mycelium, conidia, } \\
\text { appressoria and plant invasion. } \\
\text { MGG_04777: reduced invasive growth in rice }\end{array}$ & [9] \\
\hline $\begin{array}{l}\text { Fusarium } \\
\quad \text { verticillioides }\end{array}$ & FVEG_05726 & $\begin{array}{l}\text { FVEG_09897 } \\
\text { FVEG_03347 }\end{array}$ & $\begin{array}{l}\text { FvLDS1a } \\
\text { (FVEG_09294) } \\
\text { FvLDS1b } \\
\text { (FVEG_09294) } \\
\text { FVEG_11670 } \\
\text { FVEG_12540 }\end{array}$ & & $\begin{array}{l}\text { Thin, leathery \& pink mycelium; conidia more numerous with } \\
\text { faster germination, fewer perithecia when crossed with WT, } \\
\text { enhanced virulence. }\end{array}$ & [58] \\
\hline Aspergillus nidulans & & & $\begin{array}{l}\text { ppoA (AN1967) } \\
\text { ppoB (AN6320) } \\
\text { ppoC (AN5028) }\end{array}$ & & Alteration of the ratio between cleisthothecia $v s$ conidia. & [7] \\
\hline Aspergillus flavus & XP_002379215 & & $\begin{array}{l}\text { ppoA (ACO57610) } \\
\text { ppoB (ACO57611) } \\
\text { ppoC (ACO57612) } \\
\text { ppoD (ACO57613) }\end{array}$ & & Alteration of the ration of sclerotia $v s$ conidia. & \\
\hline Aspergillus fumigatus & Afu4g02770 & Afu7g00860 & $\begin{array}{l}\text { PpoA (Afu4g10770) } \\
\text { PpoB (Afu4g00180) } \\
\text { PpoC (Afu3g12120) }\end{array}$ & & $\begin{array}{l}\text { PpoC alone:Fewer conidia with faster germination, altered } \\
\text { stress resistance } \\
\text { PpoA, PpoB: no phenotype } \\
\text { PpoABC-RNAi: increased virulence \& altered stress response. }\end{array}$ & \\
\hline Ustilago maydis & & & Ssp1 (Ustma1_4571) & & $\begin{array}{l}\text { No phenotype for yeast morphology, teliospore formation, } \\
\text { mating and plant invasion. }\end{array}$ & [59] \\
\hline
\end{tabular}

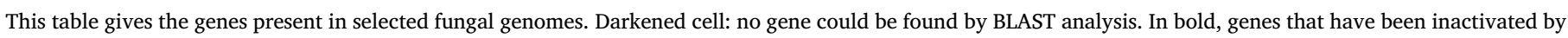
targeted gene deletion or in the case of the triple PpoABC mutant of $A$. fumigatus by RNAi.

fungi (Table 1). For the model ascomycete Aspergillus nidulans, it has been shown that specific oxylipins, known as Precocious Sexual Inducers (psi factors), play a crucial role in the balance between sexual and asexual reproduction [4, 5]. Similar roles were observed in Aspergillus flavus [6, 7], Aspergillus fumigatus [8] and Fusarium verticillioides [9]. In Trichoderma atroviride, oxylipins have been hypothesized to play a role in wounding response [10], and in Ascocoryne sarcoides in the production of eight-carbon volatile organic compounds (VOCs) [11]. Many microorganisms, both prokaryotic and eukaryotic, generate VOCs $[12,13]$. Fungal VOCs can have a variety of applications ranging from the control of bacteria and fungi [14] to clean biofuels [15]. Like oxylipins, in nature, VOCs are responsible for inter- and intra-organismic communication, leading to attraction, repulsion, as well as growth and differentiation enhancement [16]. The volatile emission profile is a consequence of specific metabolic activities of each microorganism. Fungi produce VOCs as mixtures of alcohols, ketones, esters, small alkenes, monoterpenes, sesquiterpenes, and derivatives originating from a variety of precursors [17]. They especially synthesize many VOCs with eight carbons that are responsible for the fungal odor $[18,19]$. The exact pathways used by fungi to produce these eightcarbon VOCs are not well-known [20, 21] and fungi, like plants, may utilize PUFAs and/or oxylipins to produce volatile compounds, because PUFAs may first be oxidized and then cleaved to produce the shortchain volatiles [21].

Oxylipins are synthesized in two ways, directly chemically by reactive oxygen species (ROS) [22] and indirectly by enzymes belonging to the dioxygenase family like cyclooxygenases (COX) [22], lipoxygenases (LOX) [22] or the monooxygenase family like the recentlydiscovered Abm monooxygenase [23]. Eicosanoids are supposed to be produced mainly enzymatically, while isoprostanoids mainly non-enzymatically [24-27]. Presently, the exact contribution of the enzymatic versus non-enzymatic oxidation of lipids in vivo is not well known, nor it is proven that oxylipins are indeed important precursors of VOCs in fungi $[21,28]$. Here, we describe the role of two LOX and two COX by systematic targeted gene deletion in the production of oxylipins and VOCs, as well as in the general physiology of the model fungus Podospora anserina. This fungus inhabits herbivore dung and, thanks to its rapid and easy culture and manipulation in the laboratory, is frequently used to rapidly address the role of genes [29]. We provide evidence that (1) this fungus produces isoprostanoids by an enzymatic route, (2) oxygenases are necessary for the production of some of the eight-carbon VOCs, especially 1-octen-3-ol, and (3) oxylipins and/or VOCs are used by the fungus to repel nematodes.

\section{Materials and methods}

\subsection{Strains and growth conditions}

The $P$. anserina strains (Table S1) used in this study derived from the "S" (uppercase S) wild-type strain [30] used for sequencing [31, 32]. Standard culture conditions, media and genetic methods for $P$. anserina have been described [29, 33]. The M2 medium had the following composition $\mathrm{KH}_{2} \mathrm{PO}_{4} 0.25 \mathrm{~g} / 1, \mathrm{~K}_{2} \mathrm{HPO}_{4} 0.3 \mathrm{~g} / 1, \mathrm{MgSO}_{4} / 7 \mathrm{H} 2 \mathrm{O} 0.25 \mathrm{~g} / \mathrm{l}$, Urea $0.5 \mathrm{~g} / \mathrm{l}$, Thiamine $0.05 \mathrm{mg} / \mathrm{l}$, Biotine $0.25 \mu \mathrm{g} / \mathrm{l}$, Citric Acid $2.5 \mathrm{mg} /$ 1, $\mathrm{ZnSO}_{4} 2.5 \mathrm{mg} / \mathrm{l}, \mathrm{CuSO}_{4} 0.5 \mathrm{mg} / \mathrm{l}, \mathrm{MnSO}_{4} 125 \mu \mathrm{g} / \mathrm{l}$, Boric Acid $25 \mu \mathrm{g} / \mathrm{l}$, Sodium Molybdate $25 \mu \mathrm{g} / \mathrm{l}$, Iron Alum $25 \mu \mathrm{g} / \mathrm{l}$, Dextrine $5 \mathrm{~g} / \mathrm{l}$, Agar $12,5 \mathrm{~g} / 1$. The paper medium has the same composition as M2 except that dextrin was replace by $3 \mathrm{~cm} \times 3 \mathrm{~cm}$ " $3 \mathrm{MM}$ " Whatman paper. M0 is the same as M2 except that dextrin is omitted. The N2 Bristol C. elegans strain was raised on Escherichia coli OP50.

\subsection{Chemicals}

9-hydroxy-octadecadienoic acid (9-HODE), 10-hydroxy-octadecadienoic acid (10-HODE) and 13-hydroxy-octadecadienoic acid (13HODE) were purchased from Cayman Chemical Co. (Ann Arbor, MI, USA). 16- $\mathrm{F}_{1 \mathrm{t}}$-phytoprostanes, and 9- $\mathrm{F}_{1 \mathrm{t}}$-phytoprostanes were synthesized according to published procedures [34-36].

\subsection{Gene deletions and phenotypic analysis}

The COX and LOX genes were deleted as described [29]. The primers used are reported in Table S2. After verification of the deletions by Southern blot analyses (Fig. S1), two successive crosses of the mutants 
with the wild type enabled to recover progeny strains in which potential additional interfering mutation(s) were segregated out. These F2 strains were used for phenotypic analyses. Co-segregation of the worm phenotype with the deletions (e.g., see Table 3) was further evidenced during the construction of the multiple mutants, which required additional crosses between the independently-obtained mutants. Cross $\operatorname{Lox} 1^{\Delta} \times \operatorname{Lox} 2^{\Delta}$ resulted in the recovery of $\operatorname{Lox}^{\Delta}$ and $\operatorname{Cox} 1^{\Delta} \times \operatorname{Cox} 2^{\Delta}$ in the recovery of $\operatorname{Cox}^{\Delta}$. Cross of $\operatorname{Lox}^{\Delta}$ x $\operatorname{Cox}^{\Delta}$ enabled to construct $\Delta 4$. Cosegregation of the phenotype with the deletions showed that the worm phenotype was due to the inactivation of the genes and not to some additional mutation. Phenotypes were evaluated as in [37-39] for fertility, as in [40] for paper degradation, as in [41] for constitutive peroxide and superoxide production and as in [42] for hyphal interference.

To assess effects of mycelia on worms, fungi and worms were inoculated at the same time on M2 plates or worms were inoculated three days after the fungi (Fig. S2). For the fungi, one plug of a wild-type culture and one plug of mutant culture were deposited at two distal edges of the plates. For the worms, twenty adult worms were deposited at the center of the plates. Inoculation plates were made in duplicates. Whether the fungi and worms were inoculated at the same time or at different times, the results were identical and were thus combined. Plates were then incubated at $18{ }^{\circ} \mathrm{C}$ in the dark. Locations of the worms were recorded three times per week for two weeks, at which time the two fungal cultures were still not in contact. Newborn worms hatched during the time course of the experiments and continue their development thanks to the bacteria brought up during worm inoculation (the bacteria were able to consume the M2 medium). Behavior of the newborn worms was identical to that of the adults. The results of Table 3 are the combined data of two independent experiments, i.e., of at least 8 plates for each tested WT $v s$ mutant combination. To check for the effect of opening the plates, location of the worms was recorded and the plate covers were removed (two plates for each tested WT $v s$ mutant combination). The plates were left on the bench for two hours before making a new record of worm locations. This experiment was performed twice with identical results.

\subsection{Phylogenetic analysis}

COX, LOX and Abm-like proteins were identified by BLAST using various fungal homologues as queries using the JGI mycocosm portal [43]. Alignment was made with MAFFT [44] and manually refined. This alignment was used to construct a phylogenetic tree using the maximum likelihood method (PhyML software) [45] using the default parameters and the WAG model and transferred to the iTOL server for visualization [46]. Bootstrap values are expressed as percentages of 100 replicates.

\subsection{Total fatty acid quantification}

Five mg of mat $+/$ mat- mycelium were crushed with a FastPrep ${ }^{{ }_{-}-24}$ Instrument (MP Biomedical) in $1 \mathrm{ml}$ of water $5 \mathrm{mM} \mathrm{EGTA}$ : $\mathrm{MeOH}(v / \mathrm{v}$; 1: 2); $50 \mu \mathrm{l}$ were withdrawn for protein quantification. Lipids were extracted according to Bligh and Dyer [47] in dichloromethane/methanol/water (2.5: 2.5: $2.1, \mathrm{v} / \mathrm{v} / \mathrm{v}$ ), in the presence of $2 \mu \mathrm{g}$ of glyceryl triheptadecanoate as internal standard. The lipid extracts were directly methylated in boron trifluoride methanol solution 14\% (SIGMA, $1 \mathrm{ml}$ ) and heptane $(1 \mathrm{ml})$ at RT for $1 \mathrm{~h}$ at $80^{\circ} \mathrm{C}$. After addition of water $(1 \mathrm{ml})$ to the crude, FAs were extracted with heptane $(3 \mathrm{ml})$, evaporated to dryness and dissolved in ethyl acetate $(20 \mu \mathrm{l})$. FAs extract $(1 \mu \mathrm{l})$ was analyzed by gas-liquid chromatography [48] on a Clarus 600 Perkin Elmer system using a Famewax RESTEK fused silica capillary columns ( $30 \mathrm{~m} \times 0.32 \mathrm{~mm}$ i.d, $0.25 \mu \mathrm{m}$ film thickness). Oven temperature was programmed from $110^{\circ} \mathrm{C}$ to $220^{\circ} \mathrm{C}$ at a rate of $2^{\circ} \mathrm{C}$ per min and the carrier gas was hydrogen ( $0.5 \mathrm{bar})$. The injector and the detector tempertatures were $225^{\circ} \mathrm{C}$ and $245^{\circ} \mathrm{C}$ respectively.

\subsection{Eicosanoid quantification}

For extraction, each frozen mat + /mat- mycelium $(5 \mathrm{mg})$ was crushed with a FastPrep ${ }^{\circledR}$-24 Instrument (MP Biomedical) in $1 \mathrm{ml}$ of HBSS (Invitrogen). After 2 crush cycles $(6.5 \mathrm{~m} / \mathrm{s}, 30 \mathrm{~s}), 10 \mu \mathrm{l}$ were withdrawn for protein quantification. $900 \mu \mathrm{l}$ of homogenate (around $60 \mathrm{mg}$ of tissue) were withdrawn for oxylipins analyses. $300 \mu \mathrm{l}$ of cold $-20^{\circ} \mathrm{C}$ methanol $(\mathrm{MeOH})$ and $5 \mu \mathrm{l}$ of internal standard (Deuterium labeled compounds) were added. After centrifugation at $900 \mathrm{~g}$ for $15 \mathrm{~min}$ at $4{ }^{\circ} \mathrm{C}$, supernatants were transferred into $2 \mathrm{ml}$ 96-well deep plates and diluted in $\mathrm{H}_{2} \mathrm{O}$ to $2 \mathrm{ml}$. Samples were then submitted to solid phase extraction (SPE) using HRX 96-well plate $(50 \mathrm{mg} /$ well, Macherey Nagel) pretreated with $\mathrm{MeOH}(2 \mathrm{ml})$ and equilibrated with $10 \% \mathrm{MeOH}(2 \mathrm{ml})$. After sample application, the extraction plate was washed with $10 \%$ $\mathrm{MeOH}(2 \mathrm{ml})$. After drying under aspiration, lipids mediators were eluted with $2 \mathrm{ml}$ of pure $\mathrm{MeOH}$. Prior to LC-MS/MS analysis, samples were evaporated under nitrogen gas and reconstituted in $10 \mu \mathrm{l}$ on $\mathrm{MeOH}$. LC-MS/MS analyses of eicosanoids were performed as described [49]. Briefly, lipid mediators were separated on a ZorBAX SB-C18 column $(2.1 \mathrm{~mm}, 50 \mathrm{~mm}, 1.8 \mu \mathrm{m}$, Agilent) for 9-hydroxy-octadecadienoic acid (9-HODE) and 13-hydroxy-octadecadienoic acid (13-HODE), and on a ZorBAX SB-C18 column ( $2.1 \mathrm{~mm}, 100 \mathrm{~mm}, 1.8 \mu \mathrm{m}$, Agilent) for 10-HODE using Agilent 1290 Infinity HPLC system coupled to an ESItriple quadruple G6460 mass spectrometer (Agilent Technologies). Data were acquired in Multiple Reaction Monitoring (MRM) mode with optimized conditions (ion optics and collision energy). Peak detection, integration and quantitative analysis were done using Mass Hunter Quantitative analysis software (Agilent) based on calibration lines built with commercially available eicosanoids standards (Cayman Chemicals).

\subsection{Isoprostanoid quantification}

To a total of $15 \mathrm{mg}$ of thawed mat $+/$ mat- mycelium sample, $1 \mathrm{ml}$ of Folch solution $\left(\mathrm{CHCl}_{3}: \mathrm{MeOH}, 2: 1, v / \mathrm{v}\right)$ containing $10 \mu \mathrm{BHT}(1 \%$ in ethanol) was added and spiked with $5 \mathrm{ng}$ of each internal standard $\left(\mathrm{d}_{4}-15-\mathrm{F}_{2 \mathrm{t}}\right.$-IsoP, $\mathrm{d}_{4}-10-\mathrm{F}_{4 \mathrm{t}}$-NeuroP $)$. The mixture was homogenized with a Fast Prep instrument (MP Biomedicals) for $30 \mathrm{~s}$ at $6.5 \mathrm{~m} / \mathrm{s}$. Then the homogenized tissue was further extracted with $1.5 \mathrm{ml}$ ice-cold Folch solution $\left(\mathrm{CHCl}_{3}: \mathrm{MeOH}, 2: 1, \mathrm{v} / \mathrm{v}\right)$ and $0.5 \mathrm{ml}$ of ultrapure water. The mix was shaken for $30 \mathrm{~s}$ and centrifuge for $10 \mathrm{~min}$ at room temperature to separate the aqueous and organic layers. The lower organic layer was carefully removed and transferred to a pyrex tube and then evaporated under nitrogen gas. The extracted lipid was dissolved in $1 \mathrm{ml}$ of hydrolysis solution (KOH $1 \mathrm{M}$ in $\mathrm{MeOH}$ ) and incubated at $40^{\circ} \mathrm{C}$ for $30 \mathrm{~min}$. After cooling at room temperature, $3 \mathrm{ml}$ of $40 \mathrm{mM}$ formic acid was added. Thereafter, the samples were cleaned and extracted by solidphase extraction on a 96-well plate OASIS MAX $60 \mathrm{mg}$ (Waters, USA) modified from [50]. Briefly, the wells were cleaned with $2 \mathrm{ml}$ of $\mathrm{MeOH}$ and conditioned with $2 \mathrm{ml}$ of $40 \mathrm{mM}$ formic acid ( $\mathrm{pH} 4.5$ ). After loading the samples, the wells were washed with $2 \mathrm{ml}$ of $2 \% \mathrm{NH}_{4} \mathrm{OH}$ followed by $2 \mathrm{ml}$ of $\mathrm{MeOH} / 20 \mathrm{mM}$ formic acid $(20: 80 \mathrm{v} / \mathrm{v})$ and $2 \mathrm{ml}$ of hexane. The isoprostanoids were eluted with $2 \mathrm{ml}$ hexane/ethanol/acetic acid (70:29.4:0.6 v/v/v). After drying under nitrogen gas, the samples were re-dissolved with $20 \mu \mathrm{l}$ of $\mathrm{MeOH}$. A part of the sample ( $5 \mu \mathrm{l})$ was taken for LC-MS/MS analysis using an Agilent 1290 Infinity equipped with a thermostated autosampler, a binary pump and a column oven coupled to a Agilent 6460 triple quadrupole MS (Agilent) equipped with electrospray ionization (ESI). The ESI was performed in negative ion mode. Method is described in Dupuy et al. [51]. Briefly the column was a Zorbax SB-C18 Rapid Resolution HD $(2,1 \times 100 \mathrm{~mm}$; $1,8 \mu \mathrm{m}$, Agilent). The mobile phases consisted of water: formic acid $(99.9: 0.1 ; v / v)$ (A) and acetonitrile: formic acid (99.9:0.1, v/v) (B) with a flow rate of $0.3 \mathrm{ml} / \mathrm{min}$. The analysis was performed in Selected Reaction Monitoring (SRM) detection mode using nitrogen as the collision gas. The SRM of each compound were pre-determined by MS/MS analysis. Peak 
Table 2

Proportions (\%) of the various fatty acids and oxylipins in P. anserina wild type and devoid of COX and LOX genes ( $\Delta 4$ ).

\begin{tabular}{|c|c|c|c|c|}
\hline & WT-3D & WT-8D & $\Delta 4-3 \mathrm{D}$ & $\Delta 4-8 \mathrm{D}$ \\
\hline \multicolumn{5}{|l|}{ TFA \% } \\
\hline $16: 0^{\mathrm{a}}$ & $16.68 \pm 0.42$ & $18.81 \pm 1.37$ & $14.29 \pm 1.02$ & $17.57 \pm 1.88$ \\
\hline $18: 0^{\mathrm{a}}$ & $3.21 \pm 0.77$ & $2.21 \pm 0.07$ & $2.75 \pm 0.45$ & $2.02 \pm 0.05$ \\
\hline $18: 1 w 9^{a}$ & $6.01 \pm 0.26$ & $5.55 \pm 1.58$ & $4.52 \pm 1.04$ & $5.76 \pm 1.24$ \\
\hline $18: 2 w 6^{a}$ & $51.47 \pm 8.35$ & $63.34 \pm 2.41$ & $52.88 \pm 6.80$ & $65.39 \pm 1.51$ \\
\hline $18: 3 w 3^{a}$ & $22.62 \pm 7.41$ & $10.10 \pm 5.43$ & $25.55 \pm 8.40$ & $9.25 \pm 4.59$ \\
\hline \multicolumn{5}{|l|}{ Eicosanoids \% } \\
\hline $13-\mathrm{HODE}^{\mathrm{a}}$ & $93.73 \pm 2.63$ & $70.43 \pm 9.56$ & $72.24 \pm 2.78$ & $66.15 \pm 2.14$ \\
\hline 9-HODE ${ }^{\mathrm{a}}$ & $6.27 \pm 0.70$ & $29.57 \pm 8.27$ & $27.76 \pm 2.78$ & $33.85 \pm 4.16$ \\
\hline 13-HODE +9-HODE ${ }^{\mathrm{b}}$ & 67.16 & 34.66 & 99.81 & 99.87 \\
\hline $10-\mathrm{HODE}^{\mathrm{b}}$ & 32.84 & 65.34 & 0.19 & 0.13 \\
\hline \multicolumn{5}{|l|}{ Isoprostanoids \% } \\
\hline ent-16- $\mathrm{F}_{1 \mathrm{t}}-\mathrm{Phyto} \mathrm{P}^{\mathrm{a}}$ & $34.66 \pm 0.78$ & $37.35 \pm 4.24$ & $42.64 \pm 0.60$ & 0 \\
\hline $9-\mathrm{F}_{1 \mathrm{t}}-\mathrm{Phyto \textrm {P } ^ { \mathrm { a } }}$ & $21.41 \pm 7.26$ & $18.92 \pm 4.75$ & $9.18 \pm 12.99$ & 0 \\
\hline ent-16-epi-16- $\mathrm{F}_{1 \mathrm{t}}-\mathrm{Phyto}^{\mathrm{a}}$ & $25.26 \pm 7.96$ & $22.25 \pm 1.10$ & $39.18 \pm 25.12$ & 0 \\
\hline 9-epi-9-F 1 - - PhytoP ${ }^{\mathrm{a}}$ & $18.44 \pm 14.44$ & $21.47 \pm 10.09$ & $9.00 \pm 12.73$ & 0 \\
\hline
\end{tabular}

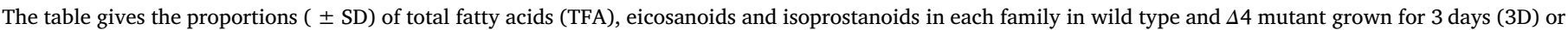
8 days (8D) on M2. Only the most abundant species for TFA are indicated, i.e., species more abundant at day 3 than $1 \mu \mathrm{g} / \mathrm{mg}$ of proteins.

a This is the percentage \pm SD for two independent lipidomic assays.

b 10-HODE was assayed separately only once, while other products were assayed twice. Comparison is thus made with the other eicosanoids from the same samples.

detection, integration and quantitative analysis were performed by Mass Hunter Quantitative analysis software (Agilent Technologies, USA).

\subsection{VOC analyses}

VOCs produced during fungal growth were collected on tubes containing a TENAX ${ }^{\circledast}$ TA absorbent (Sigma Aldrich). Sampling was active and flow rate was fixed at $10 \mathrm{ml} / \mathrm{min}$ during a time sufficient to renew at least three times chamber's volume. Desorption of TENAX ${ }^{\circledR}$ TA tubes was performed at $260^{\circ} \mathrm{C}$ for $15 \mathrm{~min}$ (ATD 400, Perkin Elmer) and cold entrapment was conditioned at $-30^{\circ} \mathrm{C}$. Temperature of transfer line between the ATD and the GC was maintained at $220^{\circ} \mathrm{C}$. VOCs were then injected simultaneously on a VF-5 ms type column (Agilent), they were separated and analyzed with a GC-MS system (GC 3800 coupled with an ion trap, Varian) as described [52, 53]. Analytical conditions were $40^{\circ} \mathrm{C}$ for $5 \mathrm{~min}, 2.5^{\circ} \mathrm{C} / \mathrm{min}$ up to $170{ }^{\circ} \mathrm{C}, 7.5^{\circ} \mathrm{C} / \mathrm{min}$ up to $250{ }^{\circ} \mathrm{C}$ and $250^{\circ} \mathrm{C}$ for $15 \mathrm{~min}$. Analytes were identified by retention time, compared with a mass spectral library (NIST 2008) and validated with the passage of a standard. VOC production was evaluated on a nutritional media made with an inert material (glass fiber pad CAT $\mathrm{N}^{\circ} 1823-025$ Whatman) in presence of M2 medium. After inoculation of mat $+/ \mathrm{mat}-$ heterokaryotic cultures, samples were placed in emission chambers [52, 54] and incubated during ten days, at $27^{\circ} \mathrm{C}$.

\subsection{Preparation of lipid peroxidation products and determination of worm avoidance}

Because lipid peroxidation products are high insoluble and sensitive to oxidation, they were extemporaneously saponified to render them bio-available [55]. To this end, $9 \pm$ HODE and $13 \pm$ HODE (cat $\mathrm{n}^{\circ} 38,400$ and 38,600 from Cayman chemical, U.S.A.) were first dissolved in ultrapure cold ethanol before being carefully dried under

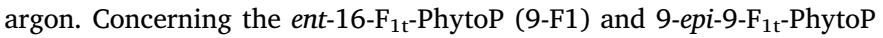
(16-F1) phytoprostanes, an aliquote of a methanolic solution was dried in the same conditions. Immediately after drying, the working solution of oxylipins or phytoprostanes were prepared by saponification in iced $\mathrm{Na}_{2} \mathrm{CO}_{3} 100 \mathrm{mM}$ aqueous solution. Aliquotes of every solutions corresponding to 12.5 nmoles of the four molecules was then put on separate Petri dishes ( $50 \mathrm{~mm}$ diameter) and 10 to 15 worms were inoculated on the opposite side of the Petri dish. The Petri dishes were immediately sealed with parafilm. Three plates for each lipid peroxidation product were processed. Worms closer than $1 \mathrm{~cm}$ to the oxidized lipds and those present in a region with an identical area located at the opposite end of the plates were counted two weeks after inoculation.

\section{Results}

\subsection{The P. anserina genome encodes four oxylipin-producing enzymes}

Mining the genome of $P$. anserina for genes coding oxylipin-producing enzymes (Table 1 ) revealed that this fungus has two genes coding for LOX of the Ile-group [56], PaLox1 (=Pa_2_4370 according to the nomenclature of the $P$. anserina genome sequencing project [32]) and PaLox2 (Pa_6_8140), and two genes coding for COX, PaCox1 (Pa 1 4690) and PaCox2 (Pa 5 1240). The P. anserina genome does not contain any gene coding for LOX enzymes of the Val-group [56] nor any homologue of the Abm monooxygenase gene [23]. Phylogenetic survey showed that LOX and COX are enzymes expendable during evolution and likely implicated in the fine tuning of the different fungal species to their environment (Figs. S3 and S4). Microarray analysis [57] confirmed the expression of the four genes in $P$. anserina and showed a downregulation of PaLox1, PaLox2 and PaCox1 in stationary phase, while the expression of PaCox 2 remained constant. To analyze their role, the four genes were inactivated by replacing their coding sequence with a resistance marker. Note that to the best of our knowledge, this is the first inactivation of genes encoding lipoxygenase of the ile group in fungi (Table 1). As different markers were used for each gene, multiple mutants could be constructed by genetic crosses, including Lox ${ }^{4}$ lacking both PaLox 1 and PaLox2, $\operatorname{Cox}^{4}$ lacking both PaCox 1 and PaCox 2 and $\Delta 4$ devoid of all four genes (Table S1). The deletions were verified by Southern blot analysis (Fig. S1 and see M \& M for subsequent genetic analysis of the mutants).

\subsection{Production of oxylipins in wild type and mutants}

Total fatty acid (TFA), free eicosanoids and total isoprostanoids contents in wild-type were assayed by GC-FID and LC-MS/MS on 3-dayold and 8-day-old mycelia grown on the M2 standard medium and proportions of each molecule was calculated for TFA, eicosanoids and isoprostanoids (Table 2). In the wild type at day 3 , TFAs were by order of decreasing proportion: linoleic (18:2 n-6), linolenic (18:3 n-3), 
palmitic (16:0), oleic (18:1) and stearic (18:0) acids. The three major detected eicosanoids were 13-hydroxy-octadecadienoic (13-HODE), 10hydroxy-octadecadienoic (10-HODE) and 9-hydroxy-octadecadienoic (9-HODE) acids (Table 2). Isoprostanoids were ent-16- $\mathrm{F}_{1 \mathrm{t}}$-phytoprostane (16F1), ent-16-epi-16-F1 t-phytoprostane (16epiisoP), 9- $\mathrm{F}_{1 \mathrm{t}}$-phytoprostane (9isoP) and 9-epi-9- $\mathrm{F}_{1 \mathrm{t}}$-phytoprostane (9F1). Note that oxylipins were in minute amounts compared to TFAs. At day 3, isoprostanoids amounted to $0.008 \mu \mathrm{g} / \mathrm{mg}$ of proteins and eicosanoids to $0.9 \mu \mathrm{g} / \mathrm{mg}$ of proteins, while TFAs amounted to $400 \mu \mathrm{g} / \mathrm{mg}$ of protein. The major differences that we observed between 3-day-old and 8-dayold wild-type mycelia were (1) the proportion of 10-HODE that increased and concomitantly that of 13-HODE that decreased and (2) a decrease in the amounts of total eicosanoids (down to $0.5 \mu \mathrm{g} / \mathrm{mg}$ of proteins) and isoprostanoids (down to $0.004 \mu \mathrm{g} / \mathrm{mg}$ of proteins), while TFA increased up to $1600 \mu \mathrm{g} / \mathrm{mg}$ of proteins. These last data are compatible with a large increase of membrane content of the mycelium, since old hyphae accumulate numerous vacuoles.

Analysis of lipids and oxylipins in the $\Delta 4$ mutants identified dramatic differences in the production of oxylipins, while minor differences were observed for TFAs (Table 2). Firstly, eicosanoids amounts were down to $0.13 \mu \mathrm{g} / \mathrm{mg}$ of proteins and $0.15 \mu \mathrm{g} / \mathrm{mg}$ of proteins at day 3 and day 8, respectively. Decrease was especially important for 10HODE since it was not produced at all. Secondly, Isoprostanoids amounts were also down especially at day 8 , since they could not be detected by our analysis. Note that at day 3 , diminution was also noticed $(0.003 \mu \mathrm{g} / \mathrm{mg}$ of proteins instead of the $0.008 \mu \mathrm{g} / \mathrm{mg}$ of proteins of the wild type). Analysis of TFA in the $\operatorname{Lox}^{\Delta}$ and $\operatorname{Cox}^{\Delta}$ did not evidence any major difference in the proportion of the various fatty acids (Table S3). However, we could not detect prostanoids in the Lox ${ }^{\Delta}$ mutant at both day 3 and day 8 and only minute amount at day $3(0.0008 \mu \mathrm{g} / \mathrm{mg}$ of proteins) and none at day 8 in the $\operatorname{Cox}^{\Delta}$ mutant (Table S3).

\subsection{Production of VOCs in WT and mutants}

VOCs production was measured by GC-MS [53] on M2 medium on an inert support (Fig. 1 \& Table 3). Our analysis identified the VOCs emitted by $m a t+/$ mat- heterokaryotic wild-type, $\operatorname{Lox}^{\Delta}, \operatorname{Cox}^{\Delta}$ and $\Delta 4$
Table 3

Some VOCs identified in wild type and mutants $\operatorname{Cox}^{\Delta}, \operatorname{Lox}^{\Delta}$ and $\Delta 4$.

\begin{tabular}{llllll}
\hline Formula & Name of compound & WT & COX $\Delta$ & LOX $\Delta$ & $\Delta 4$ \\
\hline $\mathrm{C}_{7} \mathrm{H}_{4} \mathrm{O}$ & 3-Heptanone & 0.11 & - & - & - \\
$\mathrm{C}_{7} \mathrm{H}_{6} \mathrm{O}$ & 3-Heptanol & 0.50 & - & - & - \\
$\mathrm{C}_{7} \mathrm{H}_{14} \mathrm{O}_{2}$ & Acetic acid pentyl ester & $<$ LOQ & - & - & - \\
$\mathrm{C}_{8} \mathrm{H}_{14}$ & 1,3-Octadiene & 0.87 & - & 1.15 & - \\
$\mathrm{C}_{8} \mathrm{H}_{16} \mathrm{O}$ & 1-Octen-3-ol & 0.20 & - & 0.25 & - \\
$\mathrm{C}_{8} \mathrm{H}_{16} \mathrm{O}$ & 3-Octanone & 0.19 & - & 0.51 & - \\
$\mathrm{C}_{10} \mathrm{H}_{16}$ & a-Pinene & $<$ LOQ & - & - & - \\
\hline
\end{tabular}

Under these analytical conditions LOD (Limit of detection) is $0.01 \mathrm{ppm}$ and LOQ (Limit of quantification) is $0.1 \mathrm{ppm}$ in Toluene Equivalent. The Table shows VOCs with a carbon number between $\mathrm{C}_{7}$ and $\mathrm{C}_{10}$. This is not an exhaustive list.

mycelia after ten days of incubation at which time all assayed strains had produced their fruiting bodies. The emission profiles of the wild type and each of the three mutants were different and could be clearly differentiated by principal component analysis, indicating that each strain produced specific sets of VOCs (Fig. 1). However, seven molecules clearly differentiated the wild type and mutant profiles, i.e., they were present in the wild type and not in some of the mutants (Table 3). These included three molecules with seven carbons $\left(\mathrm{C}_{7}\right)$, three molecules with eight carbons $\left(\mathrm{C}_{8}\right)$ and one monoterpene. Five out of these seven molecules are oxygenated, suggesting a possible production from oxylipins. The three $\mathrm{C}_{8}$ molecules, among which 1-octen-3-ol, were still produced in the Lox ${ }^{\Delta}$ mutant, suggesting that their synthesis relied upon the COX enzymes (Table 3).

\subsection{Phenotypic analysis of the LOX and COX mutants}

The role of PaLox1, PaLox2, PaCox1 and PaCox2 was further characterized by analyzing the phenotypes of the mutants throughout the lifecycle of the fungus. We did not detect any obvious phenotypic difference between the mutants and the wild type regarding growth, fertility on media containing various carbon sources and longevity (Fig. S5). Note that this fungus does not possess an asexual cycle, but is able to produce spermatia for fertilization purposes. Production of the
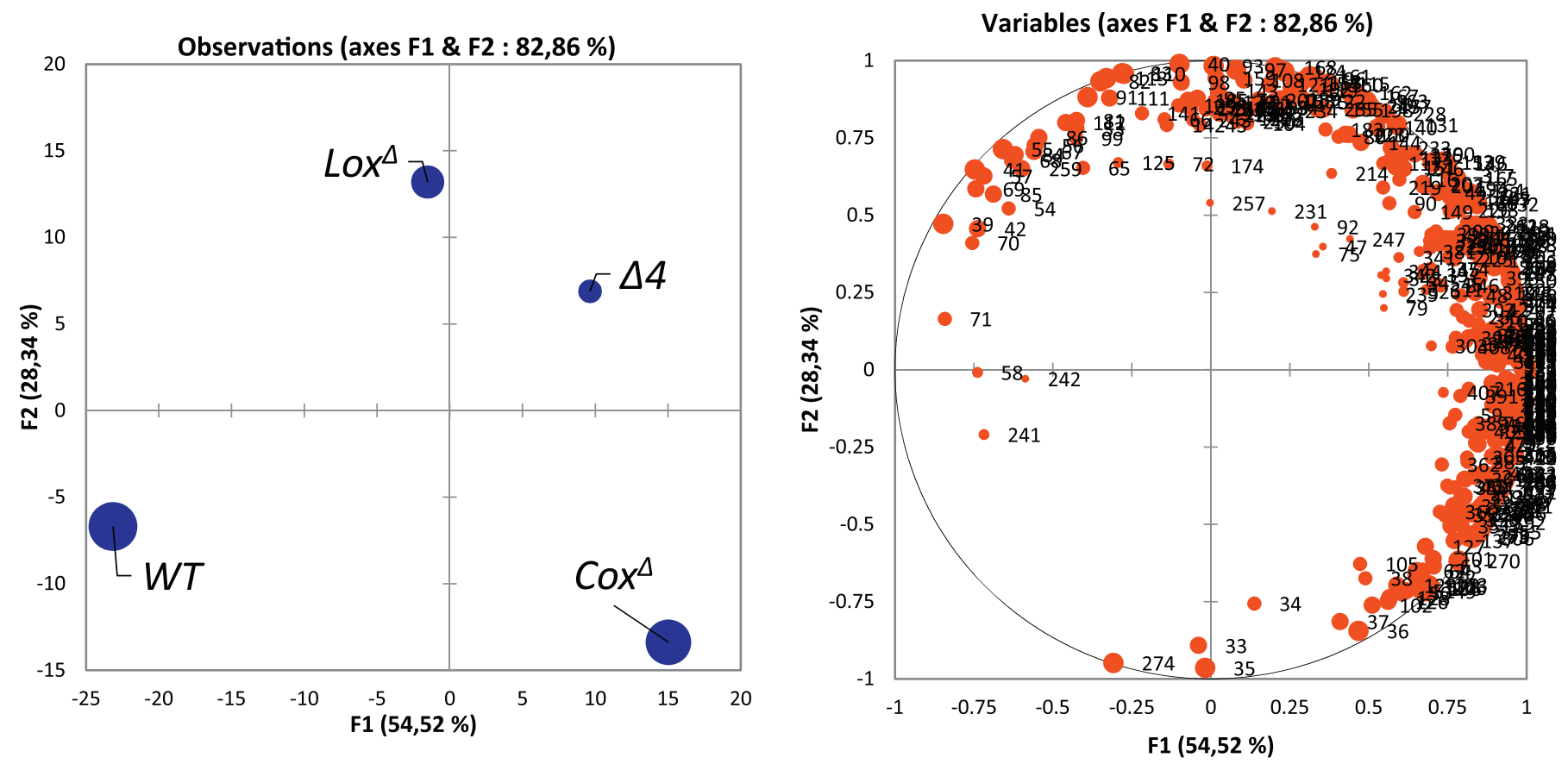

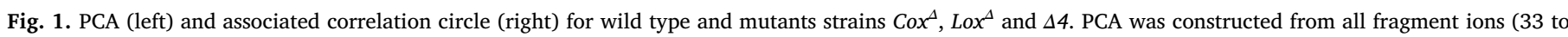

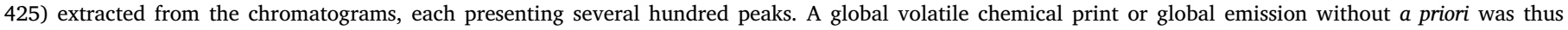
determined for each sample. Global emission of each strain is statistically different and specific. Axis 1 clearly separates wild type from mutants. 
spermatia was not modified in the mutants. In P. anserina, wounding is associated with increased ROS production as measured by DAB precipitation. This reaction was normal in all the LOX/COX mutants (Fig. S5). Hyphal Interference with Penicillium chrysogenum was also normal in the mutants (Fig. S5). This mechanism is triggered upon contact of $P$. anserina hyphae with those of $P$. chrysogenum [42]. It is associated with a ROS burst visualized by accumulation of a DAB precipitate at the contact zone between the two species, while death of $P$. chrysogenum hyphae was detected by Evans Blue coloration. We then assayed whether $P$. anserina could inhibit the growth of bacteria and fungi at a distance. To this end, we used Quadrant Petri dishes, in which two alternate quadrants were inoculated with $P$. anserina and two days later the other two with the bacteria or fungi to be assayed and the plates were sealed with parafilm. We could not detect any promoting or inhibiting effect of $P$. anserina wild type or $\Delta 4$ mutants on the growth of Corynebacterium glutamicum ATCC 13032 and Corynebacterium melassecola ATCC 17965, two species commonly found in soil, nor on that of the dung fungus Sordaria macrospora, another inhabitant of herbivore dung.

Last but not least, we assayed interactions with the nematode Caenorhabditis elegans. This worm is bacterivore and does not consume $P$. anserina (data not shown). To test whether the worms avoided or preferred the wild type versus the mutants, we inoculated the wild type and one of the mutants at distal positions in a M2 Petri dish that was populated with worms at the center (see Fig. S2 and M \& M). The plates were then incubated for several days at $18{ }^{\circ} \mathrm{C}$, which is the ideal temperature for $C$. elegans. Worms located $<2 \mathrm{~cm}$ away from the edges of the thalli were then counted three times a week. Up to 10 days of incubation at $18^{\circ} \mathrm{C}$, we did not notice any differences between the wild type and the mutants. On the contrary, after two weeks of incubation, the worms exhibited a clear avoidance of the wild-type thallus and preferred hanging near the mutant mycelium (Table 4). This was especially significant for mutants lacking the Lox 1 gene, but could also be detected in some strains devoid of the Cox2 gene. This showed that the role of the Lox and Cox genes in P. anserina was related to the synthesis of molecule(s) able to repel worms. To test if the molecules were oxylipins or their VOC degradation product(s), we repeated the experiment using the $\Delta 4$ mutants and after counting a first time, the Petri dishes were left open at room temperature $\left(\sim 20^{\circ} \mathrm{C}\right)$ for two hours, and subsequently for an additional two hours, in order to allow for the volatile compounds to withdraw from the plate and the worms to travel to other locations. As seen in Table 5, the proportion of worms avoiding the wild type mycelium was lower after opening the lid of the dishes (although they still significantly shirked the wild-type). Worm relocation was especially significant $2 \mathrm{~h}$ after opening. This strongly suggested

Table 4

Repellence activity of wild type versus mutant mycelia on C. elegans worm strain Bristol N2.

\begin{tabular}{|c|c|}
\hline Strain & Mean preference ratio \pm SD \\
\hline $\mathrm{S} / \operatorname{Cox}^{\Delta}{ }^{\Delta}$ & $1.29 \pm 0.64$ \\
\hline $\mathrm{S} / \operatorname{Cox}_{2}{ }^{\Delta}$ & $1.32 \pm 0.51_{*}$ \\
\hline S/Lox $1^{\Delta}$ & $0.83 \pm 0.44_{\text {米* }}$ \\
\hline $\mathrm{S} / \mathrm{Lox} 2^{\Delta}$ & $1.01 \pm 0.21$ \\
\hline $\mathrm{S} / \operatorname{Cox}^{\Delta}$ & $1.06 \pm 0.37_{*}$ \\
\hline S/Lox ${ }^{\Delta}$ & $0.55 \pm 0.16_{* *}$ \\
\hline $\mathrm{S} / \operatorname{Cox}^{\Delta}{ }^{\Delta} \operatorname{Lox} 1^{\Delta} \operatorname{Lox}^{\Delta}{ }^{\Delta}$ & $1.56 \pm 0.56 *$ \\
\hline $\mathrm{S} / \operatorname{Cox} 1^{\Delta} \operatorname{Cox} 2^{\Delta} \operatorname{Lox}^{\Delta}$ & $0.95 \pm 0.25$ \\
\hline $\mathrm{S} / \operatorname{Cox} 1^{\Delta} \operatorname{Cox} 2^{\Delta} \operatorname{Lox} 2^{\Delta}$ & $1.15 \pm 0.30$ \\
\hline $\mathrm{S} / \Delta 4$ & $0.73 \pm 0.11_{\text {米* }}$ \\
\hline
\end{tabular}

The table gives the ratios of worms located at the edge of the wild-type mycelium versus worms present at the edge of the indicated mutant mycelium on two-week-old plates. Statistical significance was tested by conformity chi2 with equal population size on both mycelia.

* statistically significant at 0.05 .

** statistically significant at $<0.005$.
Table 5

Effect of opening the plates on worm repulsion by the wild type.

\begin{tabular}{lll}
\hline Time after opening & \multicolumn{1}{l}{ Mean preference WT/ $\Delta 4$ ratio of \pm SD } \\
\hline 0 & $0.60 \pm 0.14_{* *} \quad$ Significantly different $p$-value $=0.035$ \\
$2 \mathrm{~h}$ & $0.82 \pm 0.30_{*}$ & \\
$4 \mathrm{~h}$ & $0.74 \pm 0.30_{* *}$ & \\
\hline
\end{tabular}

Statistical significance of difference on the worms near the wild type versus the $\Delta 4$ mutant was tested by conformity chi2 with equal population size on both mycelia. Difference on the ratios after opening the plate was made by a Student $t$-test; only the difference between 0 and $2 \mathrm{~h}$ is statistically significant.

* statistically significant at 0.05 .

** statistically significant at $<0.005$.

that the VOCs, and not the oxylipins, were likely responsible for the avoidance phenomenon, in line with the fact that $C$. elegans did not consume the fungus.

To confirm that oxidized lipids were not directly involved in deterring $C$. elegans, we assayed whether pure commercial eicosanoids and pure phytoprostanes synthesized as described in Fig. S6 were able to repel the nematodes. To this end, we tested the two commerciallyavailable eicosanoids ( $9 \pm$ HODE and $13+$ HODE) and the two phytoprostanes (9-F1 and 16-F1) that were the most abundantly synthesized by the fungus. These were rendered available to the worms by saponification (see M. \& M.) and inoculated in defined regions of Petri plates onto which worms where added. After two weeks of incubation the worms close the oxylipins and those far away from them were counted. Table 6 gives the ratios for each of the four compounds. These were not significantly different from 1 , as seen for the control without lipid peroxidation products, confirming that worm repulsion was likely not directly caused by eicosanoids and phytoprostanes. This indirectly argued that the VOCs were likely the chemicals involved in worm repulsion.

\section{Discussion}

Oxylipins are natural products that may be formed enzymatically or non-enzymatically. COX and LOX are the two major classes of enzymes involved in their production. In P. anserina, inactivation of COX and LOX genes clearly has an effect on oxylipins production. Analysis of the patterns of oxylipins in the wild type and the mutants shows that the COX and LOX enzymes may have complex activities. Firstly, they are involved in the synthesis of 10-HODE, which appears to be a major eicosanoid in $P$. anserina. These enzymes, however, have seemingly little effects on the production of 9-HODE and 13-HODE, arguing that the production of these two oxylipins is mainly non enzymatic in this fungus or catalyzed by as yet unknown enzyme(s). Intriguingly, COX and LOX enzymes appear to be involved in the synthesis of isoprostanoids that are thought to be formed non-enzymatically [24-26]. Here, we have not demonstrated whether the action of the COX and LOX enzymes is direct (i.e., they actually participate in the transformation of fatty acids into isoprostanoids) or if their action is indirect

Table 6

Lack of repulsive effect by oxylipins and phytoprostanes.

\begin{tabular}{|c|c|}
\hline & Mean preference + LPP/-LPP \\
\hline Control $^{\mathrm{a}}$ & $1.1 \pm 0.1$ \\
\hline 13- \pm HODE & $1.7 \pm 0.7$ \\
\hline $9 \pm \mathrm{HODE}$ & $0.8 \pm 0.4$ \\
\hline ent-16- $\mathrm{F}_{1 \mathrm{t}}$-PhytoP & $0.7 \pm 0.3$ \\
\hline 9-epi-9- $\mathrm{F}_{1 \mathrm{t}}$-PhytoP & $1.2 \pm 0.5$ \\
\hline
\end{tabular}

The Table gives the ratio of worms closer than $1 \mathrm{~cm}$ away from the lipid peroxidation products $(+\mathrm{LPP})$ versus those far away $(\mathrm{d}>3 \mathrm{~cm},-\mathrm{LPP})$. The ratios are not statistically different from 1 .

a Control was $100 \mathrm{mM} \mathrm{Na}_{2} \mathrm{CO}_{3}$ without lipid peroxidation products. 


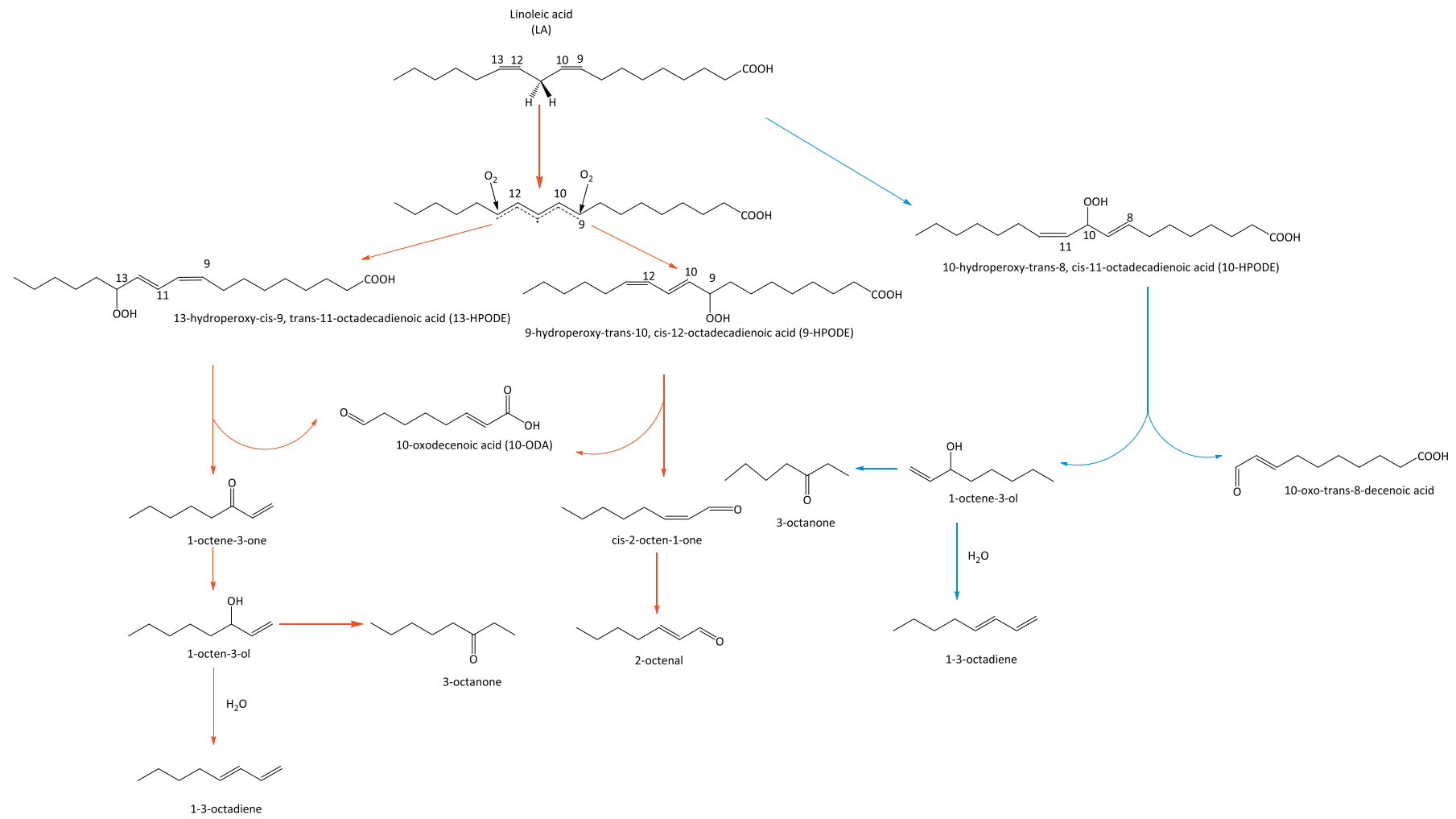

Fig. 2. Hypothesized pathways for the production of VOCs [18]. 1-3-octadiene may be synthesized through the 13-HODE pathway (in red) or through the 10-HODE pathway (in blue). (For interpretation of the references to colour in this figure legend, the reader is referred to the web version of this article.)

through modifications of the FA metabolism. Noteworthy, we observed variations of eicosanoid and isoprostanoid proportions in the wild type and mutant between day 3 and day 8 . This is correlated with variations of TFAs also in the wild type versus the mutants and day 3 versus day 8. Thus far, it is not clear whether non-enzymatic or enzymatic processes may be involved in triggering these variations. Since PaLox1, PaLox2 and PaCox1 are down-regulated as the mycelium enter stationary phase, it is not surprising to see modifications of the pattern of eicosanoids in the wild type. However, we cannot eliminate the possibility that other as-yet unknown enzymes are responsible, as the recent discovery of the Abm enzyme recently underscored in M. grisea [23].

For each mutant, the set of FA and oxylipins appears specific, a feature correlated with specific emission patterns of VOCs. Particularly, seven VOCs are missing in the $\operatorname{Cox}^{\Delta}$ and $\Delta 4$ mutants. Based on hypothesized or extrapolated pathways (Fig. 2), 1-octen-3-ol, 1,3-octadiene and 3-octanone could be produced by cleavage of 13-HODE or 10-HODE. At the present time, the exact synthesis pathway is unknown. However, these 8 carbon molecules are produced through the action of COX enzymes, since 1-octen-3-ol, 1,3-octadiene and 3-octanone are still synthesized in a strain lacking the LOX enzymes.

LOX and COX enzymes are present in many fungal genomes; however few have been analyzed by targeted gene deletion or RNAi (Table 1). The investigated enzymes are mostly from Aspergillus species and the oxylipins they produce seem involved in regulating developmental processes and secondary metabolite production. Here, analyses of the LOX and COX genes in P. anserina show that these enzymes and the oxylipins that they produce are not involved in regulating the developmental features studied here (i.e., fertility, wounding response and hyphal interference). On the contrary, the presence of LOX and COX genes is clearly associated with a repellent effect on C. elegans. To date, it is not clear which of the eicosanoids, phytoprostanes and/or VOCs are the molecules important for this effect. We showed that pure oxylipins and phytoprostanes are not able to repel worms. We also evidenced that opening of the Petri plates allowing for VOCs to be removed results in lower avoidance of the fungus by the worms. Finally, C. elegans does not consume the fungus and hence the lipid peroxidation products that are present in the membranes of the fungus. This tends to suggest that VOCs are the most likely factors responsible for worm repulsion. However, we cannot eliminate the hypothesis that oxylipins possibly in combination with VOCs also participate in repulsion. The mutants lacking LOX enzyme(s) have the strongest decrease in their repellent outcome, while they still produce 1-octen-3-ol, 1,3-octadiene and 3-octanone, suggesting that these three molecules are not the active ones. The active molecules may be some minor VOC undetected by our methods in the wild type. Volatile derivatives of isoprostanoids are good candidates, as mutants of Lox genes do not produce these oxylipins. Alternatively, the repellent effect may stem from a cocktail of VOCs rather that a single molecule.

\section{Conclusion}

In $P$. anserina, oxylipins are produced by four COX and LOX genes and are involved in providing a unique signature of VOCs. These peroxidized lipids and/or the VOCs they produce are used by the fungus to repel potential mycophagous animals. The worm $C$. elegans that we assayed here to show this effect is bacterivorous and does not consume $P$. anserina. Nevertheless, many nematodes and other small animals, such as mites, eat fungi and there is thus a clear advantage for $P$. anserina to produce noxious repellents in its natural biotope. The LOX and COX enzymes that generate these products are not present in all fungi and follow a complex evolution, as would be expected from "luxury" genes, i.e., genes coding for non-essential function, but that are important in nature to finely adapt to particular biotopes. It remains to be determined whether these enzymes and the volatile and non-volatile products they generate are used by other fungal species to also repel animals that consume them. 


\section{Conflict of interest statement}

We have no conflict of interest.

\section{Acknowledgements}

We thank Dr. Batool Ossareh-Nazari for the gift of the strain N2 of $C$. elegans and for her help in assessing that the worm does not eat $P$. anserina and Sylvie Cangemi for expert technical assistance. This work was supported by intramural funding from Université Paris 7 and by Region Ile de France (grant P3AMB).

\section{Appendix A. Supplementary data}

\section{References}

[1] H.C. Pohl, L.J. Kock, Oxidized fatty acids as inter-kingdom signaling molecules, Molecules 19 (2014).

[2] G.J. Fischer, N.P. Keller, Production of cross-kingdom oxylipins by pathogenic fungi: an update on their role in development and pathogenicity, J. Microbiol. 54 (2016) 254-264.

[3] D.I. Tsitsigiannis, N.P. Keller, Oxylipins as developmental and host-fungal communication signals, Trends Microbiol. 15 (2007) 109-118.

[4] D.I. Tsitsigiannis, R. Zarnowski, N.P. Keller, The lipid body protein, PpoA, coordinates sexual and asexual sporulation in Aspergillus nidulans, J. Biol. Chem. 279 (2004) 11344-11353.

[5] D.I. Tsitsigiannis, T.M. Kowieski, R. Zarnowski, N.P. Keller, Three putative oxylipin biosynthetic genes integrate sexual and asexual development in Aspergillus nidulans, Microbiology 151 (2005) 1809-1821.

[6] S. Horowitz Brown, R. Zarnowski, W.C. Sharpee, N.P. Keller, Morphological transitions governed by density dependence and lipoxygenase activity in aspergillus flavus, Appl. Environ. Microbiol. 74 (2008) 5674-5685.

[7] S.H. Brown, J.B. Scott, J. Bhaheetharan, W.C. Sharpee, L. Milde, R.A. Wilson, N.P. Keller, Oxygenase coordination is required for morphological transition and the host-fungus interaction of Aspergillus flavus, Mol. Plant-Microbe Interact. 22 (2009) 882-894.

[8] T.R.T. Dagenais, D. Chung, S.S. Giles, C.M. Hull, D. Andes, N.P. Keller, Defects in conidiophore development and Conidium-macrophage interactions in a dioxygenase mutant of Aspergillus fumigatus, Infect. Immun. 76 (2008) 3214-3220.

[9] V. Scala, P. Giorni, M. Cirlini, M. Ludovici, I. Visentin, F. Cardinale, A.A. Fabbri, C. Fanelli, M. Reverberi, P. Battilani, G. Galaverna, C. Dall'Asta, LDS1-produced oxylipins are negative regulators of growth, conidiation and fumonisin synthesis in the fungal maize pathogen Fusarium verticillioides, Front. Microbiol. 5 (2014).

[10] M.A. Hernandez-Onate, E.U. Esquivel-Naranjo, A. Mendoza-Mendoza, A. Stewart, A.H. Herrera-Estrella, An injury-response mechanism conserved across kingdoms determines entry of the fungus trichoderma atroviride into development, Proc. Natl. Acad. Sci. USA 109 (37) (2012) 14918-14923.

[11] T.A. Gianoulis, M.A. Griffin, D.J. Spakowicz, B.F. Dunican, C.J. Alpha, A. Sboner A.M. Sismour, C. Kodira, M. Egholm, G.M. Church, M.B. Gerstein, S.A. Strobel, Genomic analysis of the hydrocarbon-producing, cellulolytic, endophytic fungus Ascocoryne sarcoides, PLoS Genet. 8 (2012) e1002558.

[12] Y.S. Park, S. Dutta, M. Ann, J.M. Raaijmakers, K. Park, Promotion of plant growth by Pseudomonas fluorescens strain SS101 via novel volatile organic compounds, Biochem. Biophys. Res. Commun. 461 (2015) 361-365.

[13] H.A. Tahir, Q. Gu, H. Wu, W. Raza, A. Hanif, L. Wu, M.V. Colman, X. Gao, Plant growth promotion by volatile organic compounds produced by Bacillus subtilis SYST2, Front. Microbiol. 8 (2017) 171.

[14] G.A. Strobel, E. Dirkse, J. Sears, C. Markworth, Volatile antimicrobials from Muscodor albus, a novel endophytic fungus, Microbiology 147 (2001) 2943-2950.

[15] G.A. Strobel, B. Knighton, K. Kluck, Y. Ren, T. Livinghouse, M. Griffin, D. Spakowicz, J. Sears, The production of myco-diesel hydrocarbons and their derivatives by the endophytic fungus Gliocladium roseum (NRRL 50072), Microbiology 154 (2008) 3319-3328.

[16] U. Effmert, J. Kalderas, R. Warnke, B. Piechulla, Volatile mediated interactions between bacteria and fungi in the soil, J. Chem. Ecol. 38 (2012) 665-703.

[17] C. Heddergott, A.M. Calvo, J.P. Latgé, The Volatome of Aspergillus fumigatus, Eukaryot. Cell 13 (2014) 1014-1025.

[18] E. Combet, D.C. Eastwood, K.S. Burton, E. Combet, J. Henderson, J. Henderson, E. Combet, Eight-carbon volatiles in mushrooms and fungi: properties, analysis, and biosynthesis, Mycoscience 47 (2006) 317-326.

[19] R. Malheiro, P. Guedes De Pinho, S. Soares, A. César Da Silva Ferreira, P. Baptista, Volatile biomarkers for wild mushrooms species discrimination, Food Res. Int. 54 (2013) 186-194.

[20] S. Assaf, Y. Hadar, C.G. Dosoretz, 1-Octen-3-ol and 13-hydroperoxylinoleate are products of distinct pathways in the oxidative breakdown of linoleic acid by Pleurotus pulmonarius, Enzym. Microb. Technol. 21 (1997) 484-490.

[21] F. Husson, D. Bompas, S. Kermasha, J.M. Belin, Biogeneration of 1-octen-3-ol by lipoxygenase and hydroperoxide lyase activities of Agaricus bisporus, Process Biochem. 37 (2001) 177-182.

[22] E. Niki, Y. Yoshida, Y. Saito, N. Noguchi, Lipid peroxidation: mechanisms, inhibition, and biological effects, Biochem. Biophys. Res. Commun. 338 (2005) 668-676.

[23] R.N. Patkar, P.I. Benke, Z. Qu, Y.Y. Constance Chen, F. Yang, S. Swarup, N.I. Naqvi, A fungal monooxygenase-derived jasmonate attenuates host innate immunity, Nat. Chem. Biol. 11 (2015) 733-740.

[24] T. Durand, V. Bultel-Ponce, A. Guy, S. El Fangour, J.C. Rossi, J.M. Galano, Isoprostanes and phytoprostanes: bioactive lipids, Biochimie 93 (2011) 52-60.

[25] G.L. Milne, H. Yin, K.D. Hardy, S.S. Davies, L.J. Roberts, Isoprostane generation and function, Chem. Rev. 111 (2011) 5973-5996.

[26] G.L. Milne, Q. Dai, L.J. Roberts Ii, The isoprostanes-25 years later, Biochim. et Biophys. Acta (BBA) 1851 (2015) 433-445.

[27] J.M. Galano, Y.Y. Lee, C. Oger, C. Vigor, J. Vercauteren, T. Durand, M. Giera, J.C. Lee, Isoprostanes, neuroprostanes and phytoprostanes: an overview of 25years of research in chemistry and biology, Prog. Lipid Res. 68 (2017) 83-108.

[28] J.W. Bennett, A.A. Inamdar, Are some fungal volatile organic compounds (VOCs) mycotoxins? Toxins 7 (2015) 3785-3804.

[29] P. Silar, Podospora anserina: from laboratory to biotechnology, in: P.K.M. Benjamin, A. Horwitz, Mala Mukherjee, P. Christian (Eds.), Genomics of Soil- and PlantAssociated Fungi, Springer, Heidelberg New York Dordrecht London, 2013, pp. 283-309.

[30] G. Rizet, G. Delannoy, Sur la production par des hétérozygotes monofactoriels de Podospora anserina de gamétophytes phénotypiquement différents des gamétophytes parentaux, C. R. Acad. Sci. Paris 231 (1950) 588-590.

[31] P. Grognet, F. Bidard, C. Kuchly, L.C. Tong, E. Coppin, J.A. Benkhali, A. Couloux, P. Wincker, R. Debuchy, P. Silar, Maintaining two mating types: structure of the mating type locus and its role in Heterokaryosis in Podospora anserina, Genetics 197 (2014) 421-432.

[32] E. Espagne, O. Lespinet, F. Malagnac, C. Da Silva, O. Jaillon, B.M. Porcel, A. Couloux, J.M. Aury, B. Segurens, J. Poulain, V. Anthouard, S. Grossetete, H. Khalili, E. Coppin, M. Dequard-Chablat, M. Picard, V. Contamine, S. Arnaise, A. Bourdais, V. Berteaux-Lecellier, D. Gautheret, R.P. de Vries, E. Battaglia, P.M. Coutinho, E.G. Danchin, B. Henrissat, R.E. Khoury, A. Sainsard-Chanet, A. Boivin, B. Pinan-Lucarre, C.H. Sellem, R. Debuchy, P. Wincker, J. Weissenbach, P. Silar, The genome sequence of the model ascomycete fungus Podospora anserina, Genome Biol. 9 (2008) R77.

[33] G. Rizet, C. Engelmann, Contribution à l'étude génétique d'un Ascomycète tétrasporé : Podospora anserina (Ces.) Rehm, Revue de Cytologie et Biologie Végétale 11 (1949) 201-304.

[34] S. El Fangour, A. Guy, V. Despres, J.P. Vidal, J.C. Rossi, T. Durand, Total synthesis of the eight diastereomers of the syn-anti-syn phytoprostanes F1 types I and II, J. Organic Chem. 69 (2004) 2498-2503.

[35] T. Durand, A. Guy, O. Henry, J.-P. Vidal, J.-C. Rossi, C. Rivalta, A. Valagussa, C. Chiabrando, Total syntheses of four metabolites of 15-F2t-Isoprostane, Eur. J. Org. Chem. 2001 (2001) 809-819.

[36] A. Guy, C. Oger, J. Heppekausen, C. Signorini, C. De Felice, A. Furstner, T. Durand, J.M. Galano, Oxygenated metabolites of n-3 polyunsaturated fatty acids as potential oxidative stress biomarkers: total synthesis of 8-F3t-IsoP, 10-F4t-NeuroP and [D4] 10-F4t-NeuroP, Chemistry 20 (2014) 6374-6380.

[37] N. Xie, G. Ruprich-Robert, P. Silar, F. Chapeland-Leclerc, Bilirubin oxidase-like proteins from Podospora anserina: promising thermostable enzymes for application in transformation of plant biomass, Environ. Microbiol. 17 (2015) 866-875.

[38] N. Xie, F. Chapeland-Leclerc, P. Silar, G. Ruprich-Robert, Systematic gene deletions evidences that laccases are involved in several stages of wood degradation in the filamentous fungus Podospora anserina, Environ. Microbiol. 16 (2014) 141-161.

[39] A. Bourdais, F. Bidard, D. Zickler, V. Berteaux-Lecellier, P. Silar, E. Espagne, Wood utilization is dependent on catalase activities in the filamentous fungus Podospora anserina, PLoS One 7 (2012) e29820.

[40] S. Brun, F. Malagnac, F. Bidard, H. Lalucque, P. Silar, Functions and regulation of the Nox family in the filamentous fungus Podospora anserina: a new role in cellulose degradation, Mol. Microbiol. 74 (2009) 480-496.

[41] F. Malagnac, H. Lalucque, G. Lepere, P. Silar, Two NADPH oxidase isoforms are required for sexual reproduction and ascospore germination in the filamentous fungus Podospora anserina, Fungal Genetics Biol. 41 (2004) 982-997.

[42] P. Silar, Peroxide accumulation and cell death in filamentous fungi induced by contact with a contestant, Mycolol. Res. 109 (2005) 137-149.

[43] I.V. Grigoriev, R. Nikitin, S. Haridas, A. Kuo, R. Ohm, R. Otillar, R. Riley, A. Salamov, X. Zhao, F. Korzeniewski, T. Smirnova, H. Nordberg, I. Dubchak, I. Shabalov, MycoCosm portal: gearing up for 1000 fungal genomes, Nucleic Acids Res. 42 (2014) D699-D704.

[44] K. Katoh, K.-i. Kuma, H. Toh, T. Miyata, MAFFT version 5: improvement in accuracy of multiple sequence alignment, Nucl. Acids Res. 33 (2005) 511-518.

[45] S. Guindon, O. Gascuel, Simple, fast, and accurate algorithm to estimate large phylogenies by maximum likelihood, Syst. Biol. 52 (2003) 696-704.

[46] I. Letunic, P. Bork, Interactive tree of life (iTOL): an online tool for phylogenetic tree display and annotation, Bioinformatics 23 (2007) 127-128.

[47] E.G. Bligh, W.J. Dyer, A rapid method of total lipid extraction and purification, Can. J. Biochem. Physiol. 37 (1959) 911-917.

[48] J.M. Lillington, D.J. Trafford, H.L. Makin, A rapid and simple method for the esterification of fatty acids and steroid carboxylic acids prior to gas-liquid chromatography, Clin. Chim. Acta 111 (1981) 91-98.

[49] P. Le Faouder, V. Baillif, I. Spreadbury, J.P. Motta, P. Rousset, G. Chene, C. Guigne, F. Terce, S. Vanner, N. Vergnolle, J. Bertrand-Michel, M. Dubourdeau, N. Cenac, LCMS/MS method for rapid and concomitant quantification of pro-inflammatory and pro-resolving polyunsaturated fatty acid metabolites, J. Chromatogr. B 932 (2013) 
$123-133$.

[50] C.Y. Lee, A.M. Jenner, B. Halliwell, Rapid preparation of human urine and plasma samples for analysis of F2-isoprostanes by gas chromatography-mass spectrometry, Biochem. Biophys. Res. Commun. 320 (2004) 696-702.

[51] A. Dupuy, P. Le Faouder, C. Vigor, C. Oger, J.M. Galano, C. Dray, J.C. Lee, P. Valet, C. Gladine, T. Durand, J. Bertrand-Michel, Simultaneous quantitative profiling of 20 isoprostanoids from omega-3 and omega- 6 polyunsaturated fatty acids by LC-MS/ MS in various biological samples, Anal. Chim. Acta 921 (2016) 46-58.

[52] S. Moularat, E. Robine, O. Ramalho, M.A. Oturan, Detection of fungal development in a closed environment through the identification of specific VOC: demonstration of a specific VOC fingerprint for fungal development, Sci. Total Environ. 407 (2008) 139-146.

[53] S. Moularat, E. Robine, O. Ramalho, M.A. Oturan, Detection of fungal development in closed spaces through the determination of specific chemical targets, Chemosphere 72 (2008) 224-232.

[54] Y. Joblin, S. Moularat, R. Anton, F. Bousta, G. Orial, E. Robine, O. Picon, T. Bourouina, Detection of moulds by volatile organic compounds: application to heritage conservation, Int. Biodeter. Biodegr. 64 (2010) 210-217.

[55] J.P. Iliou, C. Thollon, N. Villeneuve, F. Robin, C. Cambarrat, C. Jacquemin, J.P. Vilaine, Monohydroperoxidized fatty acids but not 4-hydroxynonenal induced acute cardiac cell damage, Free Radic. Biol. Med. 19 (1995) 773-783.

[56] R. Heshof, S. Jylha, T. Haarmann, A.L. Jorgensen, T.K. Dalsgaard, L.H. de Graaff, A novel class of fungal lipoxygenases, Appl. Microbiol. Biotechnol. 98 (2014) 1261-1270.

[57] F. Bidard, E. Coppin, P. Silar, The transcriptional response to the inactivation of the PaMpk1 and PaMpk2 MAP kinase pathways in Podospora anserina, Fungal Genetics Biol. 49 (2012) 643-652.

[58] V. Scala, P. Giorni, M. Cirlini, M. Ludovici, I. Visentin, F. Cardinale, A.A. Fabbri, C. Fanelli, M. Reverberi, P. Battilani, G. Galaverna, C. Dall'Asta, LDS1-produced oxylipins are negative regulators of growth, conidiation and fumonisin synthesis in the fungal maize pathogen fusarium verticillioides, Front. Microbiol. 5 (2014) 669

[59] S.M. Huber, F. Lottspeich, J. Kamper, A gene that encodes a product with similarity to dioxygenases is highly expressed in teliospores of Ustilago maydis, Mol. Genet. Genomics 267 (2002) 757-771. 